\title{
O mapeamento do conhecimento por meio da análise SWOT: estudo em uma organização pública de saúde
}

\author{
Beatriz Rosa Pinheiro dos Santos \\ Mestranda; Universidade Estadual Paulista, Marília, SP, Brasil; \\ pinheiro.santos@unesp.br \\ Ieda Pelógia Martins Damian \\ Doutora; Universidade de São Paulo, Ribeirão Preto, SP, Brasil; \\ ieda.martins@bol.com.br
}

\begin{abstract}
Resumo: A pesquisa consiste em realizar o mapeamento de conhecimentos internos e externos em uma Unidade Básica de Saúde, que pode ser potencialmente estratégico não só para a tomada de decisões dos gestores, bem como para as práticas diárias de trabalho dos funcionários. A pesquisa contribui para os campos da Administração e da Ciência da Informação que estudam a Gestão do Conhecimento, sobretudo para a Administração Pública, incentivando a utilização de técnicas oriundas das organizações privadas no setor público, especificamente, a Matriz SWOT. Ademais, a pesquisa favorece, indiretamente, a população usuária dos serviços ofertados pela Unidade Básica de Saúde, visto que o intuito do trabalho está na busca por melhoria dos processos envolvendo os conhecimentos presentes na Unidade. Para tanto, realizou-se uma pesquisa de campo, de natureza qualiquantitativa. $\mathrm{O}$ resultado demonstrou que a unidade pesquisada apresenta muito mais pontos fracos e ameaças, do que pontos fortes e oportunidades, o que pode prejudicar a qualidade dos serviços ofertados à população.
\end{abstract}

Palavras-chave: Gestão do conhecimento. Mapeamento do conhecimento. Matriz SWOT. Setor público de saúde.

\section{Introdução}

As organizações lidam, diariamente, com um volume imenso de informação e conhecimento que são produzidos, compartilhados, recuperados e utilizados no ambiente organizacional. Assim, é incontestável o fato de que todo esse volume cause confusão aos funcionários que atuam dentro de organizações, que ainda não perceberam a importância do gerenciamento desses fatores.

Segundo Schlesinger e outros (2008), especialmente no setor público, o 
processo de mudança e de adaptação à atual sociedade do conhecimento encontra barreiras pautadas por princípios e normas tradicionais desse setor, que não costuma levar em consideração as mudanças na sociedade. Diante desse contexto, optou-se por abordar a Matriz SWOT como técnica mais comumente usada pelas organizações privadas (GOLDSCHMIDT, 2003), que pode ser adaptada e flexibilizada para aplicação também em organizações públicas, foco deste trabalho.

A Matriz SWOT é uma ferramenta de análise situacional de fatores internos e externos ligados a uma organização que serve de base para a realização de um planejamento estratégico (MCCREADIE, 2008).

O mapeamento do conhecimento, por sua vez, é considerado uma etapa/atividade de vários modelos de Gestão do Conhecimento (BUKOWITZ; WILLIAMS, 2002; PROBST; RAUB; ROMHARDT, 2002; VALENTIM, 2004), objetivando colaborar com a funcionalidade da Gestão do Conhecimento no âmbito organizacional, identificando diferentes tipos de conhecimentos que podem ser utilizados em diversas situações, tanto para a resolução de problemas quanto para o planejamento estratégico. Esse mapeamento permitirá conhecer cada funcionário, o que proporciona ao gestor um olhar mais detalhado da organização.

A partir dessas contextualizações, apresenta-se o seguinte problema de pesquisa: a aplicação da Matriz SWOT pode ser utilizada como técnica de mapeamento do conhecimento em uma Unidade Básica de Saúde? Para responder a essa questão, esse trabalho pretende realizar o mapeamento de conhecimentos internos e externos em uma Unidade Básica de Saúde que pode ser potencialmente estratégico não só para as distintas tomadas de decisões dos gestores, bem como para as práticas diárias de trabalho dos funcionários.

A pesquisa justifica-se por contribuir para os campos da Administração e da Ciência da Informação que estudam a Gestão do Conhecimento, sobretudo na Administração Pública, incentivando a utilização de técnicas oriundas e presentes na maior parte nas organizações privadas (GOLDSCHMIDT, 2003). A pesquisa, também, favorece, indiretamente, a população usuária dos serviços ofertados pela Unidade Básica de Saúde, visto que o intuito do trabalho está na 
busca por melhoria dos processos envolvendo os conhecimentos presentes na Unidade. Isso ocorre já que, uma vez mapeado os conhecimentos relativos aos pontos fortes, pontos fracos, às oportunidades e ameaças, os funcionários da organização passarão não só a planejar melhor suas atividades, como também a utilizar mais efetivamente o conhecimento exato, na situação exata e no instante exato.

Para tanto, realizou-se uma pesquisa de campo, de natureza qualiquantitativa, utilizando a matriz SWOT como possível técnica de mapeamento de conhecimentos internos e externos em uma organização. A análise dos dados contou com o método de Análise de Conteúdo, por meio da técnica categorial.

\section{Gestão do conhecimento: conceito}

Drucker (2000), um dos pioneiros da gestão do conhecimento, afirma que o conhecimento é a base para todos os setores das organizações e que estas devem criar conhecimento e dar condições para sua gestão, a fim de assegurarem sua sobrevivência no mercado de trabalho.

A gestão do conhecimento (GC) é definida por Kebede (2010) como uma junção de práticas intencionais de geração e utilização de conhecimentos, que devem associar-se a processos, pessoas e ferramentas da organização, no intuito de potencializar tomadas de decisão e obter vantagem competitiva.

Para Mattera (2014), a GC é um processo que mobiliza ferramentas, metodologias e pessoas, com o objetivo de desenvolver ambientes de aprendizagem, compartilhamento e uso do conhecimento que, por sua vez, resulta na ampliação da capacidade competitiva das organizações. Para responder às críticas que implicam ser impossível gerenciar o conhecimento, pois o mesmo é intangível e pessoal, Barbosa (2008, p. 11) afirma:

Administrar ou gerenciar o conhecimento não implica exercer controle direto sobre o conhecimento pessoal. Significa, sim, o planejamento e controle do contexto, [...] das situações nas quais esse conhecimento possa ser produzido, registrado, organizado, compartilhado, disseminado e utilizado de forma a possibilitar melhores decisões, melhor acompanhamento de eventos e tendências externas e uma contínua adaptação da empresa a 
condições sempre mutáveis e desafiadoras do ambiente onde a organização atua.

Carvalho (2012) corrobora que o papel da GC não é mecanizar a capacidade de criar conhecimento em momentos já pré-definidos, mas sim de propiciar um ambiente e um processo de criação de conhecimento que ocorra de maneira natural, como consequência de um ambiente adequado e sinérgico para a criação do conhecimento organizacional.

Esse ambiente sinérgico pode ser estabelecido por meio do desenvolvimento das seguintes atividades-base de GC destacadas por Valentim:

a) identificar demandas e necessidades de conhecimento;

b) mapear e reconhecer fluxos informais;

c) desenvolver a cultura organizacional positiva em relação ao compartilhamento/socialização de conhecimento;

d) proporcionar a comunicação informacional de forma eficiente, utilizando tecnologias de informação e comunicação;

e) criar espaços criativos dentro da corporação;

f) desenvolver competências e habilidades voltadas ao negócio da organização;

g) criar mecanismos de captação de conhecimento, gerado por diferentes pessoas da organização;

h) desenvolver sistemas corporativos de diferentes naturezas, visando o compartilhamento e uso de conhecimento;

i) fixar normas e padrões de sistematização de conhecimento;

j) retroalimentar o ciclo.

Pode-se dizer que o cumprimento dessas atividades-base é uma forma de promover um ambiente propicio para o estabelecimento da GC no ambiente organizacional. Além de Valentim (2004), Takeuchi e Nonaka (2008) afirmam que uma organização gerencia o conhecimento quando:

a) cria espaços favoráveis à troca de experiências;

b) admite erros;

c) favorece intercâmbios entre seus colaboradores; 
d) reconhece e valoriza a diversidade;

e) reconhece e valoriza seus talentos;

f) busca sempre a inovação;

g) dissemina a cultura da visão compartilhada;

h) sistematiza e organiza o conhecimento adquirido;

i) permite a redundância;

j) reconhece no conflito um inicio de "caos criativo";

k) valoriza a gerência intermediária;

1) incentiva a delegação e a autonomia;

m)investe em capacitação;

n) propicia elementos para a visão sistêmica;

o) utiliza a tecnologia como uma ferramenta de apoio;

p) possibilita acessos às informações em todos os níveis;

q) incentiva a criatividade;

r) propicia ambientes lúdicos.

Diante das atividades explanadas por Valentim (2004) e Nonaka e Takeuchi (2008), pode-se afirmar que a GC apresenta muitas tarefas que, se entendidas e realizadas, resultam em aspectos positivos para a organização, visto que, de acordo com Longo (2014), a GC não habita onde não existem condições adequadas para a criação do conhecimento.

Todavia, diante da grande quantidade de informação que permeia o ambiente das organizações e, também, diante da grande quantidade de conhecimento decorrente dessa informação, o funcionário tem uma vasta necessidade de conhecer quais são exatamente os conhecimentos efetivos presentes no ambiente organizacional, quais os conhecimentos necessários para determinadas situações e como obtê-los. Isso quer dizer que o mapeamento do conhecimento passa a ser um processo imprescindível da GC, que tem a capacidade de auxiliar os funcionários no ato de utilização efetiva dos conhecimentos que flutuam entre os distintos setores organizacionais.

Para Behr (2010), o mapeamento do conhecimento pode ser considerado uma ferramenta da GC que busca avaliar não somente os conhecimentos de uma organização, mas aqueles que serão fundamentais para o desenvolvimento das 
práticas de trabalho em um plano operacional e, concomitantemente, para a tomada de decisões no contexto tático e estratégico. Para o autor, a aplicação dessa ferramenta de mapeamento identifica potencialidades, bem como insuficiências de conhecimentos advindos dos funcionários em um âmbito organizacional.

De acordo com Jarrar (2002), não é possível entender e compreender os conhecimentos presentes no ambiente organizacional sem a realização da tarefa de mapeamento do conhecimento que identifica como e onde o conhecimento é desenvolvido na organização, qual o seu fluxo e quais os funcionários que detêm conhecimento sobre determinados assuntos e aspectos.

Dessa maneira, a fim de realizar o mapeamento do conhecimento na organização pesquisada, foram utilizados não só aspectos do Modelo de Gestão do Conhecimento para a administração pública de Batista (2012), como também a técnica de análise SWOT, criada por Albert Humphrey que, segundo Morris (2005), pode ser considerada um plano de estratégia que visa mapear conhecimentos internos e externos ligados a uma organização, visando atingir com efetividade os distintos objetivos organizacionais.

\section{Matriz SWOT}

Segundo Andrade e outros (2008), a técnica SWOT é uma ferramenta de análise que procura identificar a informação correspondente aos pontos fortes e fracos no ambiente interno de uma organização, bem como as oportunidades e ameaças no ambiente externo. O termo S.W.O.T é composto em sigla, derivado da língua Inglesa, traduzindo-se em Strenghts (Forças), Weaknesses (Fraquezas), Opportunities (Oportunidades) e Threats (Ameaças).

Surgiu na década de 1960, por meio de discussões entre acadêmicos da administração que passaram a ressaltar a importância do ato de identificar informações e conhecimentos pertinentes a "forças", "fraquezas", “oportunidades" e "ameaças" das organizações (ANDRADE et al., 2008).

Para Tarapanoff (2001), a técnica SWOT está presente no mundo há mais de três mil anos, mas lhe foi atribuída maior relevância nas décadas de 1960 e 1970, 
mediante uma pesquisa realizada por Albert Humphrey que utilizou a técnica com o intuito de otimizar o planejamento de inúmeras organizações na época.

Em um contexto abrangente e de interação, a GC tem o objetivo de não só dar condições aos atos de valorização do capital intelectual das organizações, como também de utilizar um maior número de estratégias que possibilitem um olhar menos mecânico e mais reflexivo sobre a importância das informações que permeiam as organizações e os conhecimentos concernentes aos funcionários.

Dessa forma, visualizar a técnica $S W O T$ como uma técnica potencial da GC pode ser classificado como importante, tanto para o âmbito prático das organizações como para o contexto acadêmico de pesquisas, justamente, porque, de acordo com Ghemawat (2000), o objetivo da técnica é captar informação e conhecimento que apresentem capacidade de definir estratégias para manter pontos fortes, reduzir pontos fracos, aproveitar as oportunidades e se proteger das ameaças. Além disso, pode-se dizer que a inserção dessa técnica em uma organização pública carrega consigo um resultado ainda mais inovador e significativo.

Johnson, Scholes e Whittington (2007) corroboram que a ferramenta SWOT, mais do que apenas mapear a situação de uma organização, também permite que as organizações utilizem suas forças e fraquezas para lidar com as ameaças e, ao mesmo tempo, explorar as oportunidades que surgem no ambiente organizacional.

Com base nessas contextualizações, pode-se dizer que, independente do ambiente organizacional, seja público ou privado, a aplicação da técnica $S W O T$ pode ser uma prática relevante, uma vez que sua finalidade é mapear informações, conhecimentos e situações gerais sobre uma organização, a fim de auxiliar no processo de tomada de decisões e nas articulações estratégicas voltadas às práticas diárias dos funcionários. A técnica pode ser adaptada, até mesmo, pelo campo da Ciência da Informação, em convergência com a gestão da informação e gestão do conhecimento que tem como um dos seus objetivos o próprio mapeamento. 


\section{Metodologia}

Foi realizada uma pesquisa de campo de natureza qualiquantitativa em uma organização pública, caracterizada como uma Unidade Básica de Saúde. O objetivo da pesquisa foi mapear conhecimentos internos e externos da Unidade e analisá-los em benefício da organização, utilizando a Matriz SWOT adaptada em Escala de 'Likert', a fim de medir o nível de concordância e consciência dos funcionários sobre os possíveis conhecimentos relativos aos pontos fortes, pontos fracos, oportunidades e ameaças da organização.

Esse instrumento foi aplicado em 12 funcionários de uma Unidade Básica de Saúde, dentre eles: enfermeiros, atendentes de Saúde, técnicos em Enfermagem e médicos, profissionais esses que compõem o quadro de profissionais de saúde da Unidade. Além disso, o instrumento para coleta de dados foi aplicado por meio eletrônico, desenvolvido com auxílio da ferramenta “Google Forms". O questionário esteve disponível aos respondentes, de 15 a 22 de Setembro de 2017, e o convite para preenchimento foi realizado por ligação telefônica e formalizado por e-mail. Optou-se por esse método de aplicação pelo fato de propiciar ao respondente maior liberdade e conforto para explicitação da resposta, afinal, o mesmo é considerado, segundo Andrade e outros (2008), como autoaplicado, ou seja, não há a figura do aplicador/pesquisador.

Para análise dos dados, empregou-se o método de Análise de Conteúdo de Bardin (2009), utilizando-se a técnica de análise categorial, a fim de obter as características qualitativas do estudo. Para analisar os conhecimentos afirmativos da Escala de 'Likert', foi utilizado o cálculo do Ranking Médio (RM) proposto por Oliveira (2005), com o objetivo de obter as características quantitativas do estudo e tabular o mapeamento dos conhecimentos existentes na Unidade. Conforme o grau de concordância, afirmação e dissertação dos funcionários, o cálculo do RM atribui um valor de um a cinco para cada resposta, calculando-se a média ponderada para cada afirmação da escala, conforme a frequência das respostas.

Também, é relevante explicitar que quanto mais próximo de cinco o RM estiver, maior será o nível de concordância dos funcionários, e quanto mais próximo de um, menor será aquele nível. 
A Unidade Básica de Saúde pesquisada neste artigo atende, aproximadamente, a uma área de oito mil habitantes e tem como objetivo prestar atendimento de nível básico à população. Esse tipo de unidade é considerado uma das bases mais importantes do Sistema Único de Saúde, pois é capaz de resolver, aproximadamente, $80 \%$ dos problemas de saúde dos pacientes, como também apresenta autonomia para triagem e encaminhamento de pacientes para outras unidades de referências que atendem a agravos com maior complexidade (BRASIL, 2002).

Diariamente, essa unidade realiza atividades voltadas à cura de agravos e à prevenção dos mesmos, por meio de algumas práticas, como: consultas médicas, exames preventivos, oferta de medicamentos, procedimentos de vacina, curativos e inalação, encaminhamento e agendamento de pacientes a outras especialidades, consultas odontológicas, entre outros serviços correlatos.

Enfim, por uma análise preliminar de campo realizada nesta unidade, pôde-se perceber que a mesma é dotada de profissionais com experiências e culturas distintas: alguns deles já trabalharam no setor privado e outros apenas no setor público, o que, de forma natural, gera convergências no modo com que cada um realiza suas tarefas e interage.

\section{Resultados e discussão}

Nesta seção serão discutidos os resultados do estudo, com base na aplicação do questionário (matriz SWOT adaptada em escala de Likert).

O questionário aplicado nessa pesquisa contém 24 afirmações que estabelecem aos respondentes os seguintes graus de concordância: (i) concordo totalmente, (ii) concordo, (iii) nem concordo, nem discordo, (iv) discordo e (v) discordo totalmente. Cabe destacar que o questionário foi desenvolvido com base nas Diretrizes operacionais da Unidade Básica de Saúde, desenvolvida por Ribeiro e outros (2015). Na Tabela 1, expõem-se a Média Ponderada (MP) e o valor do Ranking Médio (RM) para cada afirmação do questionário, de acordo com as respostas dos profissionais. 
Tabela 1 - Resultados da aplicação do questionário 'Matriz SWOT adaptada em escala de Likert'

$\begin{array}{ccc} & \text { MÉDIA } & \text { RANKING } \\ \text { AFIRMAÇÕES } & \text { PONDERADA } & \text { MÉDIO (RM) }\end{array}$

$\begin{aligned} & \text { 1. A avaliação epidemiológica e social do } \\ & \text { território de cobertura da Unidade é }\end{aligned}$
costumeiramente realizada.

2. Os profissionais buscam identificar $28 \quad 2,33$ instituições parceiras e equipamentos sociais que podem beneficiar os serviços da Unidade.

\begin{tabular}{l}
$\begin{array}{l}\text { 3. Reuniões em grupos acontecem de maneira } \\
\text { frequente na Unidade. }\end{array}$ \\
$\begin{array}{l}\text { 4. O compartilhamento da informação e do } \\
\text { conhecimento acontece entre os profissionais }\end{array}$ \\
$\begin{array}{l}\text { e o gestor. } \\
\begin{array}{l}\text { 5. Programas externos de capacitação são } \\
\text { disponibilizados e aplicados aos profissionais } \\
\text { da Unidade. }\end{array}\end{array}$ \\
\hline
\end{tabular}

6. A administração do horário de $47 \quad 3,92$
funcionamento da Unidade acontece de maneira efetiva.
7. O cumprimento do horário de funcionamento é realizado efetivamente.

8. Os arquivos da Unidade são mantidos sempre atualizados e organizados.

$\begin{aligned} & \text { 9. O cadastro dos pacientes é sempre } \\ & \text { atualizado. }\end{aligned}$
$\begin{aligned} & \text { 10. A equipe de regulação local externa } \\ & \text { oferece apoio satisfatório à Unidade. }\end{aligned}$
$\begin{aligned} & \text { 11. O agendamento de consultas na Unidade } \\ & \text { é sistematicamente organizado. }\end{aligned}$
$\begin{aligned} & \text { 12. Os profissionais acessam e utilizam o } \\ & \text { Prontuário Eletrônio do Paciente com }\end{aligned}$

Prontuário Eletrônico do Paciente com eficiência.

13. Os profissionais acreditam que o
Prontuário Eletrônico do Paciente é um
sistema efetivo para melhorias dos serviços
ofertados aos pacientes.

14. A Unidade oferece estrutura física e $36 \quad 3,00$ equipamentos adequados aos pacientes.

\begin{tabular}{|c|c|c|}
\hline $\begin{array}{l}\text { 15. Os profissionais gerenciam as ações, a } \\
\text { fim de reduzir questões burocráticas que } \\
\text { dificultam o papel de resolução dos } \\
\text { problemas dos pacientes. }\end{array}$ & 35 & 2,92 \\
\hline $\begin{array}{l}\text { 16. A sala de vacina é mantida em } \\
\text { funcionamento durante todo o expediente, } \\
\text { incentivando, a todo o momento, a }\end{array}$ & 28 & 2,33 \\
\hline
\end{tabular}




\begin{tabular}{|c|c|c|}
\hline $\begin{array}{l}\text { 17. O setor de medicação é mantido em } \\
\text { funcionamento durante todo o expediente. }\end{array}$ & 26 & 2,17 \\
\hline $\begin{array}{l}\text { 18. O teste imunológico de Gravidez é } \\
\text { garantido aos pacientes durante todo o } \\
\text { expediente. }\end{array}$ & 51 & 4,25 \\
\hline $\begin{array}{l}\text { 19. A coleta de Papanicolau é frequentemente } \\
\text { ofertada aos pacientes. }\end{array}$ & 46 & 3,83 \\
\hline $\begin{array}{l}\text { 20. A relação e o controle de medicamentos } \\
\text { da farmácia encontram-se inseridos e em } \\
\text { conformidade com o sistema de informação } \\
\text { da Unidade. }\end{array}$ & 24 & 2,00 \\
\hline $\begin{array}{l}\text { 21. Os pacientes são orientados quanto ao } \\
\text { uso correto do medicamento receitado, em } \\
\text { relação: à posologia, aos efeitos colaterais e } \\
\text { às reações adversas. }\end{array}$ & 35 & 2,92 \\
\hline $\begin{array}{l}\text { 22. A relação dos serviços oferecidos pela } \\
\text { Unidade Básica de Saúde permanece sempre } \\
\text { em local visível e de fácil acesso aos } \\
\text { pacientes. }\end{array}$ & 43 & 3,58 \\
\hline $\begin{array}{l}\text { 23. Compreendo o que é 'Totem de } \\
\text { pesquisa'. }\end{array}$ & 31 & 2,58 \\
\hline $\begin{array}{l}\text { 24. Existe a necessidade de serviço de } \\
\text { ouvidoria para atender às demandas e } \\
\text { reclamações. }\end{array}$ & 42 & 3,50 \\
\hline
\end{tabular}

Fonte: Dados da pesquisa.

A partir dos resultados do questionário 'Matriz SWOT adaptada em Escala de 'Likert', demonstrados na Tabela 1, e de acordo com o critério de mapeamento e tabulação das afirmações expostas no Capítulo 3, pode-se dizer que as afirmações que se destacaram na concordância dos profissionais e que atingiram em RM entre três e cinco foram: (6) a administração do horário de funcionamento da unidade acontece de maneira efetiva; (7) o cumprimento do horário de funcionamento é realizado efetivamente; (14) a unidade oferece estrutura física e equipamentos adequados aos pacientes; (18) o teste imunológico de gravidez é garantido aos pacientes durante todo o expediente; (19) a coleta de Papanicolau é, frequentemente, ofertada aos pacientes; (22) a relação dos serviços oferecidos pela unidade básica de saúde permanece sempre em local visível e de fácil acesso aos pacientes; (24) existe a necessidade de serviço de ouvidoria para atender às demandas e reclamações. 
Deve-se atentar, também, para as demais afirmações/conhecimentos que ficaram entre 1 e 2,99, visto que não obtiveram destaque e entraram em níveis de discordâncias entre os profissionais.

Para uma análise qualitativa desses resultados, empregou-se o método de 'Análise de Conteúdo' de Bardin (2009), utilizando a técnica de 'análise categorial', na qual as categorias foram definidas 'a priori', tendo como base fundamentos da MATRIZ SWOT. No Quadro 1, constam as categorias para posterior análise.

Quadro 1 - Categorias e inferências para análise dos dados

\begin{tabular}{|c|}
\hline $1^{\circ}$ Categoria: Pontos fortes da Unidade \\
\hline INFERÊNCIA \\
\hline $\begin{array}{l}\text { Atividades e práticas internas que são eficientemente realizadas e que retornam } \\
\text { em aspectos positivos à organização. }\end{array}$ \\
\hline $2^{\circ}$ Categoria: Pontos fracos da Unidade \\
\hline INFERÊNCIA \\
\hline $\begin{array}{l}\text { Atividades e práticas internas que não são eficientemente realizadas e que } \\
\text { colaboram para o retorno de aspectos negativos à organização. }\end{array}$ \\
\hline $3^{\circ}$ Categoria: Oportunidades para a Unidade \\
\hline INFERÊECIA \\
\hline $\begin{array}{l}\text { Tipos de ações práticas, informações e conhecimentos construídos fora da } \\
\text { Unidade e por outras organizações que podem contribuir para a organização } \\
\text { como oportunidades de crescimento. }\end{array}$ \\
\hline $4^{\circ}$ Categoria: Ameaças para a Unidade \\
\hline INFERÊENCIA \\
\hline $\begin{array}{l}\text { Tipos de ações práticas, informações, conhecimentos e características do } \\
\text { ambiente externo que podem impedir o bom desenvolvimento organizacional } \\
\text { efetivo. }\end{array}$ \\
\hline
\end{tabular}
Fonte: Elaborado pelas autoras.

Com base na primeira categoria - pontos fortes da Unidade -, notou-se que a administração do horário de funcionamento da unidade acontece de maneira efetiva $(\mathrm{RM}=3,92)$, assegurando o bom funcionamento $\mathrm{e}$ disponibilidade dos profissionais aos pacientes. Isso quer dizer que esse aspecto contribui para a quebra de paradigma de que o setor público não cumpre à risca o horário de funcionamento. Por sua vez, isso reflete na satisfação dos funcionários, com a atual administração, que cumprem o horário de funcionamento estipulado $(\mathrm{RM}=3,92)$ de maneira eficaz. 
Outro ponto relevante diz respeito à estrutura física e equipamentos adequados $(\mathrm{RM}=3,00)$ que são oferecidos aos profissionais que atuam na unidade. De acordo com a análise, esse aspecto é visto como um dos pontos fortes da organização, juntamente com a garantia de oferta do teste imunológico de gravidez durante todo o expediente $(\mathrm{RM}=4,25)$, e da coleta de Papanicolau $(\mathrm{RM}=3,58)$.

Claramente, a oferta frequente desses serviços demonstra o comprometimento da organização com a população assistida, além do correto cumprimento das diretrizes operacionais da Unidade Básica de Saúde. Por último, destaca-se, também, como ponto forte desta organização, o fato de que a relação dos serviços oferecidos permanece sempre em local visível e de fácil acesso aos pacientes $(\mathrm{RM}=3,58)$. Isso porque, ao adentrar-se à unidade, é importante que o paciente tenha todas as informações disponíveis, referentes aos horários e tipos de profissionais que estão atendendo, a fim de que ele possa decidir, perante sua necessidade, qual serviço encontra-se disponível para utilização.

Em relação à segunda categoria - pontos fracos da Unidade' -, pode-se afirmar que, de acordo com os resultados do RM abaixo de três, algumas afirmações podem ser alocadas como pontos fracos da organização, que necessitam ser trabalhados e melhor desenvolvidos para se tornarem conhecimentos ativos e pontos fortes da organização.

Por exemplo, a frequência de reuniões em grupos dentro da unidade (RM $=2,08$ ) é uma prática importante para a otimização do fator comunicacional entre os profissionais, além de dar condições à criação de novas ideias, perante a exposição de conhecimentos guardados pelos profissionais. Geralmente, essas reuniões estimulam as relações interpessoais e auxiliam no processo de socialização e compartilhamento da informação e do conhecimento entre os profissionais e o gestor $(\mathrm{RM}=2,17)$ que, de acordo com o resultado dessa pesquisa, também é uma prática pouco estimulada dentro do ambiente organizacional pesquisado. A falta de socialização e compartilhamento da informação e conhecimento entre o profissional e o gestor pode acarretar problemas, como a desmotivação do funcionário e falhas na execução das 
práticas de trabalho. Além disso, barra condições do desenvolvimento da gestão do conhecimento dentro da organização.

Além desses pontos fracos, notou-se, também, que a organização e a atualização dos arquivos e documentos da unidade $(\mathrm{RM}=2,50)$ não estão sendo mantidas pelos profissionais, e, como consequência dessa cultura de desorganização de arquivos, o cadastro dos pacientes não é sempre atualizado $(\mathrm{RM}=2,00)$ como deveria. Tocou-se no fator cultural, justamente, porque as organizações, em geral, não tem, em sua estrutura, a escalação de um profissional da informação (arquivista, bibliotecário, cientista da informação) que possa instruir e realizar esses serviços. Esse aspecto, infelizmente, pode contribuir para a perda de informações confidenciais e importantes para o processo decisório, além de dificultar a realização das práticas diárias de trabalho, visto que toda ação depende de informação e conhecimento bem organizados e gerenciados.

Em relação ao prontuário eletrônico do paciente, pôde-se notar que os profissionais ainda não foram conscientizados da efetividade do sistema para melhoria dos serviços ofertados, pois a afirmação relativa à eficiência no acesso e uso do prontuário eletrônico do paciente $(\mathrm{RM}=2,08)$ obteve um $\mathrm{RM}$ abaixo do esperado, considerando-se que a unidade apresenta uma implantação e uma utilização efetiva desse sistema. Esse fato refletiu na falta de sistematização dos agendamentos de consultas da unidade $(\mathrm{RM}=2,08)$. No contexto em que $\mathrm{o}$ prontuário eletrônico do paciente já é uma realidade e uma premissa estipulada às unidades da Atenção Básica, torna-se imprescindível que os gestores dessas unidades realizem um trabalho de mudança e adequação cultural dos profissionais a essa nova realidade, a fim de otimizar ainda mais a produção, a gestão e o uso da informação nesses ambientes organizacionais.

Fatores como manter a sala de vacina em funcionamento durante todo o expediente, incentivando a atualização vacinal $(\mathrm{RM}=2,17)$, são também diretrizes operacionais da Unidade Básica de Saúde. A unidade mencionada apresentou resultados insatisfatórios, adentrando-se ao conjunto de pontos fracos da organização que prejudicam a eficiência da oferta de serviço integral à população. 
A relação e o controle de medicamentos da farmácia, em conformidade com o sistema de informação da unidade $(\mathrm{RM}=2,00)$, também constituem fatores que devem ser melhorados e delegados aos profissionais responsáveis, assim como a orientação aos pacientes sobre uso correto do medicamento receitado, em relação à posologia, efeitos colaterais e reações adversas (RM = 2,92). Todos esses fatores, se melhorados internamente, resultarão em ações internalizadas que, com o tempo, se transformarão em conhecimento tácito e efetivo para o bom desenvolvimento da organização.

No âmbito da terceira categoria - Oportunidades para a Unidade -, considerou-se o serviço de ouvidoria para atender às demandas e reclamações $(\mathrm{RM}=3,50)$, uma prática relacionada aos profissionais da unidade. É notável que esse serviço externo seja uma oportunidade de crescimento organizacional, visto que funcionará também como um mapeamento de informações externas advindas dos pacientes, como também servirá de canal de comunicação entre população e unidade, ou seja, o acesso à informação pelos funcionários será muito mais facilitado.

Por último, na quarta categoria - Ameaças para a Unidade -, concluiu-se que a realização costumeira de avaliação epidemiológica e social do território de cobertura da unidade $(\mathrm{RM}=2,25)$ apresentou resultado insatisfatório, que pode oferecer risco à organização. Tal avaliação traz informações territoriais e situacionais externas dos pacientes e da população em geral, e pode servir de base para o desenvolvimento do planejamento estratégico para a execução de novas práticas que atendam à demanda populacional, de acordo com as características avaliadas.

A prática dos profissionais, que visa identificar instituições parceiras e equipamentos sociais que podem beneficiar os serviços da unidade $(R M=2,33)$, pela análise, confirmou não ser uma prática costumeira no ambiente organizacional. Essa falta de estabelecer vínculos profissionais e sociais com outras instituições externas à organização pode acarretar riscos no crescimento qualitativo dos serviços da unidade. Ou seja, atentar para esse fator significa transferir-se do grupo de riscos para o grupo de oportunidades. 
Outro fator relacionado a essa prática e que também não apresentou bom resultado na análise foi a aplicação de programas externos de capacitação aos profissionais da unidade $(\mathrm{RM}=2,83)$. Em verdade, esse resultado é consequência do resultado anterior, pois, a partir do instante em que a unidade potencializar suas parcerias com outras instituições, a possibilidade de essas oferecerem cursos e capacitações diversas à unidade será muito maior.

Toda unidade básica de saúde apresenta em seu eixo padrão de funcionamento uma equipe de regulação local externa, que deve estar apta a oferecer apoio à unidade $(\mathrm{RM}=1,00)$. Nesta pesquisa, observou-se que a equipe responsável por prestar apoio a essa unidade não está auxiliando de maneira efetiva, pois os profissionais mostraram-se insatisfeitos em suas respostas. Podese afirmar que uma prestação de serviço de qualidade, com rapidez e eficácia, por parte dessas equipes reguladoras, pode influenciar a forma de atendimento e execução das ações. Esse é um fator de risco muito claro e não envolve apenas aspectos internos da organização. Dessa maneira, é importante que os profissionais sejam influenciados e conscientizados a gerenciar as ações a fim de reduzir questões burocráticas que dificultam o papel de resolução dos problemas dos pacientes $(\mathrm{RM}=2,92)$. Assim, eles poderão contribuir para mudar a imagem do serviço público de saúde que, muitas vezes, é considerado um sistema puramente burocrático e vagaroso.

Mais uma prática que pode ser considerada uma oportunidade à organização, mas que pelo baixo resultado adentrou-se no grupo de riscos, é a indagação a respeito do grau de compreensão dos profissionais sobre o que é totem de pesquisa $(\mathrm{RM}=2,58)$. Eles demonstraram desconhecer o que é totem de pesquisa, portanto, presume-se que essa não seja uma estratégia inclusa e utilizada no ambiente organizacional pesquisado, dificultando o desenvolvimento de um processo tão importante à gestão, isto é, o feedback dos pacientes sobre os serviços que estão sendo oferecidos e a relação dos níveis de satisfação para esses serviços.

Assim, com o intuito de apresentar de maneira sistematizada os conhecimentos mapeados e organizados em pontos fortes, pontos fracos, oportunidades e ameaças à organização pesquisada, elaborou-se o Quadro 2. 
Quadro 2 - Mapeamento do conhecimento de acordo com a análise SWOT

\begin{tabular}{|c|c|}
\hline $\begin{array}{c}\text { TIPOS DE } \\
\text { CONHECIMENTO }\end{array}$ & CONHECIMENTOS MAPEADOS \\
\hline \multirow{6}{*}{ Pontos Fortes $(\mathrm{F})$} & $\begin{array}{l}\text { A administração do horário de funcionamento da } \\
\text { Unidade acontece de maneira efetiva. }\end{array}$ \\
\hline & $\begin{array}{l}\text { O cumprimento do horário de funcionamento é } \\
\text { realizado efetivamente. }\end{array}$ \\
\hline & $\begin{array}{l}\text { A Unidade oferece estrutura física e equipamentos } \\
\text { adequados aos pacientes. }\end{array}$ \\
\hline & $\begin{array}{l}\text { O teste imunológico de gravidez é garantido aos } \\
\text { pacientes durante todo o expediente. }\end{array}$ \\
\hline & $\begin{array}{l}\text { A coleta de Papanicolau é frequentemente ofertada aos } \\
\text { pacientes. }\end{array}$ \\
\hline & $\begin{array}{l}\text { A relação dos serviços oferecidos pela Unidade Básica } \\
\text { de Saúde permanece sempre em local visível e de fácil } \\
\text { acesso aos pacientes. }\end{array}$ \\
\hline \multirow{11}{*}{ Pontos Fracos $(\mathrm{O})$} & $\begin{array}{l}\text { Reuniões em grupos não acontecem de maneira } \\
\text { frequente na Unidade. }\end{array}$ \\
\hline & $\begin{array}{l}\text { O compartilhamento da informação e do conhecimento } \\
\text { não acontece entre os profissionais e o gestor. }\end{array}$ \\
\hline & $\begin{array}{l}\text { Os arquivos da Unidade não são mantidos sempre } \\
\text { atualizados e organizados. }\end{array}$ \\
\hline & O cadastro dos pacientes não é sempre atualizado. \\
\hline & $\begin{array}{l}\text { O agendamento de consultas na Unidade não é } \\
\text { sistematicamente organizado. }\end{array}$ \\
\hline & $\begin{array}{l}\text { Os profissionais não acessam e não utilizam o } \\
\text { Prontuário Eletrônico do Paciente com eficiência. }\end{array}$ \\
\hline & $\begin{array}{l}\text { Os profissionais não acreditam que o Prontuário } \\
\text { Eletrônico do Paciente seja um sistema efetivo para } \\
\text { melhorias dos serviços ofertados aos pacientes. }\end{array}$ \\
\hline & $\begin{array}{l}\text { A sala de vacina não é mantida em funcionamento } \\
\text { durante todo o expediente, incentivando a todo o } \\
\text { momento a atualização vacinal. }\end{array}$ \\
\hline & $\begin{array}{l}\text { O setor de medicação não é mantido em } \\
\text { funcionamento durante todo o expediente. }\end{array}$ \\
\hline & $\begin{array}{l}\text { A relação e o controle de medicamentos da farmácia } \\
\text { não se encontram inseridos e em conformidade com o } \\
\text { sistema de informação da Unidade. }\end{array}$ \\
\hline & $\begin{array}{l}\text { Os pacientes não estão sendo orientados quanto ao uso } \\
\text { correto do medicamento receitado, em relação: à } \\
\text { posologia, aos efeitos colaterais e às reações adversas, } \\
\text { de maneira eficiente. }\end{array}$ \\
\hline Oportunidades $(\mathrm{F})$ & $\begin{array}{l}\text { Implantação do serviço de ouvidoria para atender às } \\
\text { demandas e reclamaçôes. }\end{array}$ \\
\hline Ameaças (A) & $\begin{array}{l}\text { A avaliação epidemiológica e social do território de } \\
\text { cobertura da Unidade não é costumeiramente } \\
\text { realizada. }\end{array}$ \\
\hline
\end{tabular}




\begin{tabular}{|l|l|}
\hline & $\begin{array}{l}\text { Os profissionais não buscam identificar instituições } \\
\text { parceiras e equipamentos sociais que podem beneficiar } \\
\text { os serviços da Unidade. }\end{array}$ \\
\cline { 2 - 3 } & $\begin{array}{l}\text { Programas externos de capacitação não são } \\
\text { disponibilizados e aplicados aos profissionais da } \\
\text { Unidade. }\end{array}$ \\
\hline $\begin{array}{l}\text { A equipe de regulação local externa não oferece apoio } \\
\text { satisfatório à Unidade. }\end{array}$ \\
\hline $\begin{array}{l}\text { Os profissionais não gerenciam as ações, a fim de } \\
\text { reduzir questões burocráticas que dificultam o papel de } \\
\text { resolução dos problemas dos pacientes. }\end{array}$ \\
\hline $\begin{array}{l}\text { Os profissionais não compreendem o que é 'Totem de } \\
\text { pesquisa'. }\end{array}$ \\
\hline
\end{tabular}

Fonte: Elaborado pelas autoras.

Esse quadro tem o objetivo de nortear e condensar os resultados da pesquisa, que teve como intuito mapear conhecimentos de uma unidade básica de saúde, de acordo com a Matriz SWOT.

\section{Considerações finais}

Buscou-se com pesquisa responder ao seguinte problema: a aplicação da Matriz SWOT pode ser utilizada como técnica de mapeamento do conhecimento em uma Unidade Básica de Saúde? Assim, objetivou-se realizar o mapeamento de conhecimentos internos e externos em uma Unidade Básica de Saúde que pode ser potencialmente estratégico não só para as distintas tomadas de decisões dos gestores, bem como para as práticas diárias de trabalho dos profissionais.

A gestão do conhecimento pode ser definida como uma ferramenta que objetiva cuidar do conhecimento advindo do ser humano. Em uma organização, ela tem como intuito dar condições aos profissionais para que eles aprendam, acessem informações, as internalizem e as transformem em conhecimento, que poderá ser utilizado justamente para a tomada de decisão diária. Além do mais, uma das tarefas mais importantes da gestão do conhecimento é o mapeamento do conhecimento que objetiva destacar e colocar em evidência os tipos de conhecimentos que se encontram presentes no ambiente organizacional e pertencem à equipe de profissionais que nele atuam. A prática de mapear o 
conhecimento deve ser constantemente realizada, principalmente, para auxiliar os gestores no conhecimento de seus profissionais e suas habilidades.

Dessa maneira, realizou-se um mapeamento de conhecimento, baseado na análise $S W O T$, e, assim, classificaram-se os conhecimentos em pontos fortes, pontos fracos, oportunidades e ameaças a uma Unidade Básica de Saúde. Em síntese, notou-se que a unidade pesquisada tem números de pontos fracos e ameaças muito maiores que os pontos fortes e oportunidades, o que pode prejudicar totalmente a qualidade dos serviços ofertados à população.

Para isso, é necessário gerenciar as ameaças e fazer com que se transformem em oportunidades de crescimento organizacional; implantar definitivamente o serviço de ouvidoria para atender às demandas e reclamações, aproveitando a oportunidade já mapeada; atentar para os pontos fracos e trabalhar para que eles transformem-se em pontos fortes; e continuar a potencializar os pontos fortes já existentes na organização.

Pôde-se refletir que a Matriz SWOT adaptada ao setor público é uma ferramenta eficiente de gestão que pode ser utilizada como técnica de mapeamento do conhecimento em uma Unidade Básica de Saúde.

O trabalho apresentou limitações referentes à complexidade que estão agregadas aos conceitos trabalhados, principalmente, no que se refere a uma abordagem inovadora, relacionando tais conceitos. Mesmo assim, acredita-se que a ciência cresce conforme a busca de relações que auxiliam na união dos campos científicos e, assim, como apoio ao desenvolvimento de pesquisas futuras, inter-relacione conceitos oriundos tanto da Ciência da Informação como da Administração. Indicam-se investigações que visem identificar o nível de maturidade em gestão do conhecimento de uma Unidade Básica de Saúde, utilizando como ferramenta o modelo APO-KM.

\section{Agradecimentos}

À Coordenação de Aperfeiçoamento de Pessoal de Nível Superior (CAPES), pelo financiamento da pesquisa. 


\section{Referências}

ANDRADE, J. C. et al. Aplicação da análise SWOT para identificar oportunidades para o desenvolvimento econômico e social. In: ENCONTRO LATINO AMERICANO DE PÓS-GRADUAÇÃO, 9., 2008, São José dos Campos. Anais... São José dos Campos: Universidade do Vale do Paraíba, 2008. p. 1-6.

BARBOSA, R. R. Gestão da Informação do Conhecimento: origens, polêmicas e perspectivas. Informação \& Informação, Londrina, v. 13, n. esp., p. 1-25, 2008.

BARDIN, L. Análise de conteúdo. 4. ed. Lisboa: Edições 70, 2009.

BATISTA, F. F. Modelo de gestão do conhecimento para a administração pública brasileira: como implementar a gestão do conhecimento para produzir resultados em benefício do cidadão. Brasília: Ipea, 2012.

BEHR, A. Mapeamento de competências na pequena empresa de software: o caso da ABC Ltda. 2010. Dissertação (Mestrado em Administração) - Escola de Administração, Universidade Federal do Rio Grande do Sul, Porto Alegre, 2010 .

BRASIL. Ministério da Saúde. Conselho Nacional de Saúde. O desenvolvimento do Sistema Único de Saúde: avanços, desafios e a reafirmação dos seus princípios e diretrizes. Brasília: Ministério da Saúde, 2002.

BUKOWITZ, W. R.; WILLIAMS, R. L. Manual de gestão do conhecimento: ferramentas e técnicas que criam valor para a empresa. Porto Alegre: Bookman, 2002.

CARVALHO, F. C. A. Gestão do conhecimento. São Paulo: Pearson, 2012.

DRUCKER, P. F. As informações de que os executives realmente precisam. In: HARVARD BUSINESS REVIEW (Ed.). Medindo o desempenho empresarial. Rio de Janeiro: Campus, 2000. p. 9-30.

GHEMAWAT, P. A estratégia: e o cenário dos negócios. Porto Alegre: Bookman, 2000.

GOLDSCHMIDT, A. Análise SWOT na captação de recursos: avaliação de oportunidades, ameaças, pontos fortes e pontos fracos. Integração: Revista Eletrônica do Terceiro Setor, Rio de Janeiro v. 1, n. 6, p. 1-, 2003.

JARRAR, Y. F. Knowledge management: learning for organizational experience. Managerial Auditing Journal, Reino Unido, v. 17, n. 6, p. 322328, 2002. 
JOHNSON, G.; SCHOLES, K.; WHITTINGTON, R. Explorando a estratégia corporativa. 7. ed. Porto Alegre: Bookman, 2007.

KEBEDE, G. Knowledge management: an information science perspective.

International Journal of Information Management, San Diego, v. 30, n. 5, p. 416-424, Oct. 2010.

LONGO, R. A importância do conhecimento e do profissional da informação para a estratégia corporativa num contexto de complexidade. In: SOUTO, L. F. (Org.). Gestão da informação e do conhecimento: práticas e reflexões. Rio de Janeiro: Interciência, 2014.

MATTERA, T. C. Gestão do conhecimento na prática. In: SOUTO, L. F. (Org.). Gestão da informação e do conhecimento: práticas e reflexões. Rio de Janeiro: Interciência, 2014. p.199-220.

MCCREADIE, K. A arte da Guerra SUN TZU: uma interpretação em 52 ideias brilhantes. São Paulo: Globo, 2008.

MORRIS, D. O modelo da oportunidade. HSM Managment, São Paulo, v. 5, n. 52, p. 56-62, 2005.

OLIVEIRA, L. H. Exemplo de cálculo de ranking médio para Likert. 2005. Notas de Aula da Disciplina Metodologia Científica e Técnicas de Pesquisa em Administração, Programa de Pós-Graduação na Área de Administração, Faculdade Cenecista de Varginha, Varginha, 2005.

PROBST, G.; RAUB, S.; ROMHARDT, K. Gestão do conhecimento: os elementos constitutivos do sucesso. Porto Alegre: Bookman, 2002.

RIBEIRO, C. L. M. R. et al. Unidade Básica de Saúde: diretrizes operacionais. São Paulo: CESCOM/SMS, 2015.

SCHLESINGER, C.C.B. et al. Gestão do conhecimento na administração pública. Curitiba: Instituto Municipal de Administração Pública, 2008.

TAKEUCHI, H.; NONAKA, I. Gestão do conhecimento. Porto Alegre: Bookman, 2008.

TARAPANOFF, K. Inteligência organizacional e competitiva. Brasília: UnB, 2001.

VALENTIM, M. L. P. Gestão da informação e gestão do conhecimento: especificidades e convergências. Londrina: Infohome, 2004. 


\title{
Knowledge mapping through SWOT analysis: a study in a public health organization
}

\begin{abstract}
The research consists in mapping the internal and external knowledge in a Basic Health Unit, which can be potentially strategic not only for managers' decision making, but also for the daily work practices of employees. The research contributes to the fields of Administration and Information Science, which study Knowledge Management, especially for Public Administration, encouraging the use of techniques that come from private organizations in the public sector, specifically the SWOT Matrix. Moreover, the research indirectly favors the user population of the services offered by the Basic Health Unit, since the aim of the work is to improve the processes involving the knowledge present in the Unit. For that, a field research of a qualitative and quantitative nature was carried out. The result showed that the unit surveyed present many more weaknesses and threats than strengths and opportunities, which may harm the quality of the services offered to the population.
\end{abstract}

Keywords: Knowledge management. Knowledge mapping. SWOT analysis. Public health sector.

Recebido: 02/10/2017

Aceito: $13 / 03 / 2018$ 